\title{
Outcome Based Medical Curriculum: Features, Standards and Challenges
}

\author{
Youhasan $P^{l}$, Sivanjali $M^{2}$, Sathaananthan $T^{3}$
}

\begin{abstract}
Outcome based education has become vital in Medical curriculum worldwide. It's practiced successfully in many countries. After evidencing the practice worldwide, Eastern University, Sri Lanka (EUSL) developed its curriculum to outcome based.

Identifying educational programme outcome is crucial process in outcome based educational practice. The educational outcomes of MBBS programme of EUSL have been matched with international standards. The graduate profile reflects the attributes of graduates, which is physician's potentials at the end of the course. Constructive alignment of curriculum is exhibited in accordance with the Sri Lanka Medical Council (SLMC) guidelines, MBBS programme outcome, the organization of learning contents, teaching learning experiences to achieve the intended learning outcomes and assessments for learning. Assessments for learning (formative assessments) are conducted at the end of the modules and feedbacks are expected to be given to drive the learning. Educational outcomes involve several competencies such as Knowledge, Skills and Attitude. There are several assessment methods have been followed to assess various attributes in EUSL. Teacher takes part in facilitating learning or mentoring students.

Assessing the team work skills, critical thinking, problem solving are also the salient features as this outcome based medical curriculum has been implemented to foresee the graduates treating patients in a holistic manner.

Keywords: Outcome-Based Medical Curriculum, Graduate Profile, Constructive alignment, Intended Learning Outcomes, Competencies, Eastern University, Sri Lanka.
\end{abstract}

\section{Introduction}

Outcome based model is an educational approach driven by the outcomes that the student should display by the end of a course ${ }^{1}$. Spady defined that "An outcome is a culminating demonstration of learning; it is what the student should be able to do at the end of the course"2. Outcome based education has become vital in medical curriculum worldwide and it is practiced successfully in many countries ${ }^{3}$. The outcome based education is greatly emphasized on learning rather than teaching ${ }^{4}$. Constructive alignment of the outcome based curriculum is a framework which illustrates the arrangement of learning environment that enables learners to achieve the intended learning outcomes ${ }^{5}$. Curriculum planners need to focus on what sort of physician they would like to produce for the society. In order to implement, medical education faces greater challenges for physician training all over the world. Eastern University, Sri Lanka is a one of state medical institution offering MBBS programme (medical

\footnotetext{
1. Lecturer, Department of Medical Education \& Research, Eastern University, Sri Lanka.

2. Lecturer, Department of Medical Education \& Research, Eastern University, Sri Lanka.

3. PhD Research Scholar, Centre for Medical Education, University of Dundee, Scotland.
}

Address of correspondence: P. Youhasan

Lecturer, Department of Medical Education \& Research, Faculty of Health-Care Sciences, Eastern University, Sri Lanka.

Email: youhasanp@esn.ac.lk graduation) in Sri Lanka. After considering current healthcare needs and the acceptable practice worldwide, Eastern University, Sri Lanka (EUSL) revised its curriculum into outcome based by identifying graduate profile. The outcome based medical curriculum was implemented in 2016.

This review paper is written with the aim of describing the features, standards and challenges of outcome based curriculum.

\section{Features of Outcome Based Medical Curriculum}

\section{Programme Outcome:}

Programme outcomes are statements that describe the wider attributes of a graduate, which are expected to be developed by the end of the MBBS programme 6 . It is also known as exit outcomes $^{2}$. The following programme outcomes have been identified for the MBBS programme in EUSL. It is formulated on the basis of the Sri Lanka Medical Council (SLMC) Guidelines.
Scientific knowledge in medical practice
Clinical and procedural skills
Patient management
Medico-legal work
Health promotion and disease prevention
Communication and interpersonal skills
Teamwork and leadership

Bangladesh Journal of Medical Education 2019;10(1):34-38. (C) 2019 Youhasan et al., publisher and licensee Association for Medical Education. This is an Open Access article which permits unrestricted non-commercial use, provided the original work is properly cited. 
Problem solving and research

Planning and management

Ethics and professionalism

Lifelong learning and continuing professional development

\section{Graduate profile:}

Graduate profiles are descriptions of knowledge, skills and attitudes, which a university community intends that her graduates will develop through their study to equip them for their future education or employment. These descriptions are written at institution and qualification level, and are used to inform curriculum design as well as guide the development of learning outcomes, teaching-learning activities and assessment at educational programme level ${ }^{7}$. The following graduate profiles are identified at EUSL for medical graduate to demonstrate at the end of MBBS programme.

Diagnose and manage health and disease relating the normal and deranged structure and function of the human body

Recognize and manage emergency health situations and take preventive measures

Recognize disease outbreaks and epidemics at local, national and global level and take appropriate actions

Carryout basic medico legal procedures including postmortem examination

Apply principles of behavioral sciences, ethics and professionalism in health and promote peace

Use statistical methods and demographic data in practice of health care

Function as an effective member or leader of a health team recognizing their different roles

Carry out research studies in patient care / public health and disseminate the findings

Demonstrate self-learning in education and practice

Counsel and educate patients and their families with empathy

Implement health promotion and educational activities to prevent illness and disability at individual and community level

Use information technology in learning and practice of healthcare

Communicate effectively in English, Sinhala and Tamil with patients, families and health-care team

\section{Intended learning Outcome:}

Intended learning outcomes (ILOs) are the specific statements that develop for courses or modules to achieve the programme outcome. ILO is specifically described what the learner to be able to do/do better at the end of the module or course. The figure-1 describes how the ILOs influencing on the programme outcome and graduate profile.

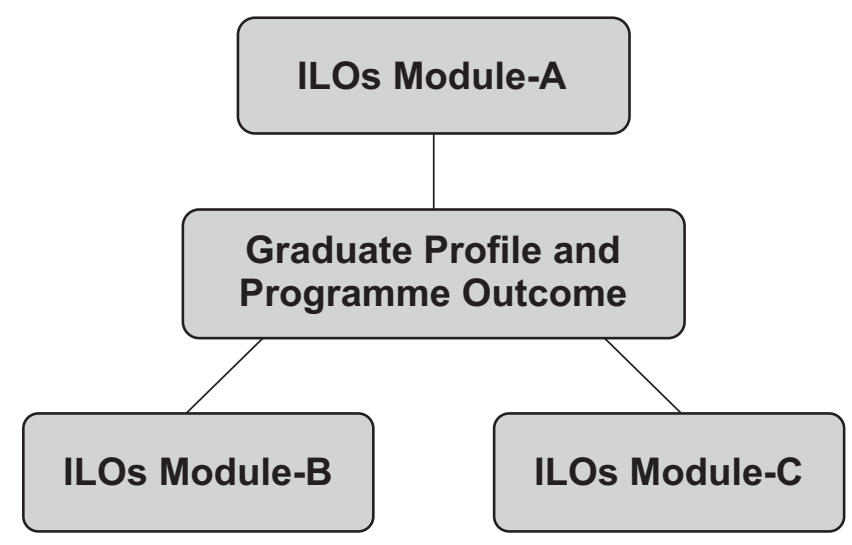

Figure 1: Influence ILO on the Programme Outcome

ILO involves several educational domains such as knowledge, skills and attitudes. Furthermore, the ILOs are written on the basis of Bloom's taxonomies. As the MBBS programme is under the seventh level of Sri Lankan Qualification Framework (SLQF), the high order ILOs (as per the Bloom's taxonomies) are entertained in the curriculum while considering the $7^{\text {th }}$ level descriptors of the SLQF.

\section{Curriculum Alignment}

Constructive alignment is a design that describes the organization of learning contents, teaching learning experiences and assessment to achieve the intended learning outcomes. Moreover, it shows the alignment of educational environment with learning outcomes ${ }^{8}$.

\section{Teaching Learning Approaches}

The Outcome based teaching learning approaches are focused not on what the teacher intends to teach, rather the emphasis is on what is the outcome from the learner of that teaching is intended to be ${ }^{9}$. The teaching learning (T-L) methods should align with learning outcomes (figure-2). Furthermore, the educational domain (Knowledge, skill and attitude) of a particular ILO is triggered by teaching learning method.

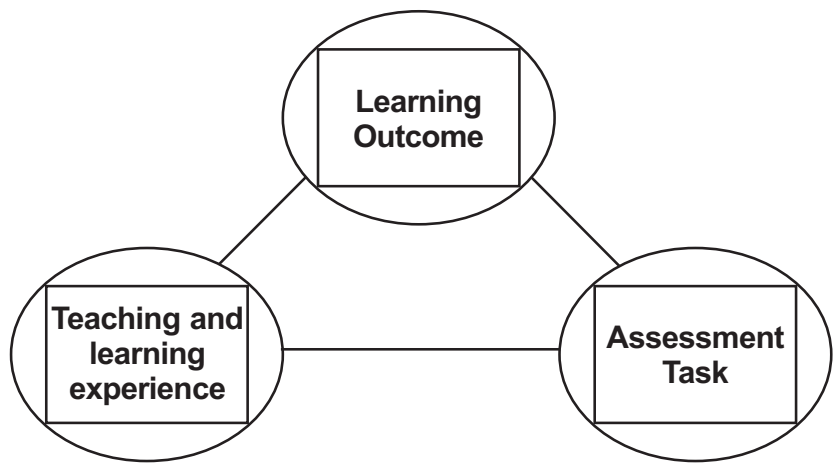

Figure 2: Biggs' theory of constructive alignment adapted from (Biggs, 1999) 
The student centric T-L approaches are mainly incorporated in the outcome based educational practice. The following TL methods are practiced in FHCS, EUSL namely interactive lecture, group discussion, demonstration, case-based learning, problem-based learning, simulation, role play, fishbowl observation, tutorial, self-directed learning, experiential learning, laboratory work, fieldwork, assignment and peer tutoring. Session plan of the modules are prepared by curriculum planners. It is included as session number, learning experience, assessment methods, ILOs and its' alignment on the programme outcome.

\section{Assessment}

Assessment strategies and methods must ensure that the knowledge, skills and attitudes set out previously are sufficiently covered ${ }^{10}$. Meantime the Australian Medical Council stated that the assessments is a systematic process for measuring and providing feedback on the candidate's progress, level of achievement or competence, against defined criteria ${ }^{11}$. Formative and summative assessments with various assessment methods such as Multiple Choice Question (MCQ), Objective Structured Clinical Examination (OSCE), Objective Structured Practical Examination (OSPE), Structured Essay Question (SEQ) are designed in the EUSL MBBS curriculum to confirm the achievement of ILO and programme outcome. The choice of assessment method is mainly based on the ILOs' educational domains and its' taxonomies. It has been illustrated in Figure-3.nstructive alignment adapted from (Biggs, 1999)

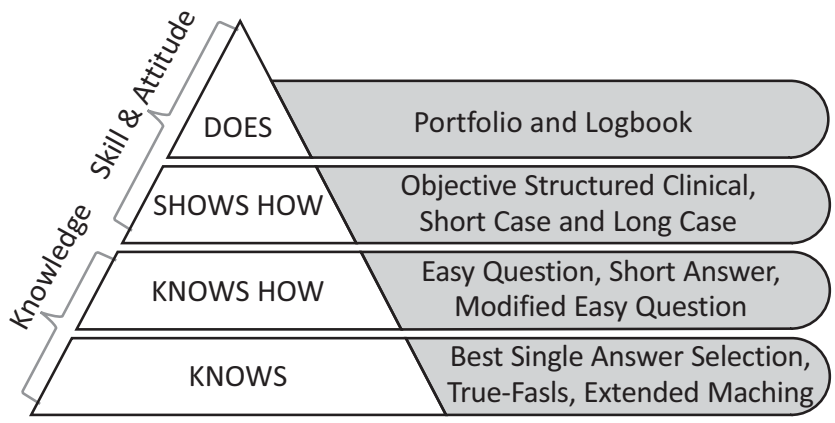

Figure 3: Assessment Methods adopted with Millers' Pyramid

\section{Standards}

In addition to SLMC guidelines and SLQF, few international standards such as CanMEDS, General Medical Council (GMC) standards and the Accreditation Council for Graduate Medical Education (ACGME) competencies have been taken into consideration while developing EUSL medical curriculum.

CanMEDS is a framework for improving patient care by enhancing physician training in Canada. It was developed by the Royal College in the 1990s. Its main purpose is to define the necessary competencies for all areas of medical practice and provide a comprehensive foundation for medical education and practice in Canada. Since its formal adoption by the Royal College in 1996, CanMEDS has become the most widely accepted and applied physician competency framework in the world ${ }^{12}$. GMC states that Medical students are tomorrow's doctors. In accordance with good medical practice, graduates will make the care of patients as their first concern, applying their knowledge and skills in a competent and ethical manner and using their ability to provide leadership and to analyze difficult and uncertain situations ${ }^{13}$. ACGME is an independent, non-profitable, regulatory body responsible for accrediting the majority of graduate medical training programs for physicians in the United States ${ }^{14}$. The alignment of EUSL programme outcome which is highly associated with international standards is explained in Table-1.

Bangladesh Journal of Medical Education 2019;10(1):34-38 
Table-1: The alignment of EUSL Programme outcome with international standards

\begin{tabular}{|c|c|c|c|c|c|c|c|c|c|c|c|c|}
\hline \multirow{2}{*}{ Standards } & \multirow{2}{*}{ Outcome } & \multicolumn{11}{|c|}{ Programme Outcome of MBBS Programme at EUSL } \\
\hline & & 1 & 2 & 3 & 4 & 5 & 6 & 7 & 8 & 9 & 10 & 11 \\
\hline \multirow{6}{*}{ 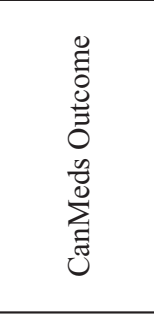 } & Professional & XXX & XXX & XXX & $\mathrm{XX}$ & $\mathrm{XX}$ & XXX & $\mathrm{XXX}$ & $\mathrm{XX}$ & XXX & $\mathrm{XXX}$ & $\mathrm{XX}$ \\
\hline & Communicator & $\mathrm{X}$ & $\mathrm{XX}$ & XXX & $\mathrm{X}$ & $\mathrm{XX}$ & $\mathrm{XXX}$ & $\mathrm{XXX}$ & $\mathrm{XX}$ & $\mathrm{XX}$ & $\mathrm{XX}$ & $\mathrm{X}$ \\
\hline & Collaborator & $\mathrm{X}$ & $\mathrm{X}$ & $\mathrm{XXX}$ & $\mathrm{X}$ & $\mathrm{X}$ & $\mathrm{XX}$ & $\mathrm{XXX}$ & $\mathrm{XX}$ & $\mathrm{XX}$ & $\mathrm{X}$ & $\mathrm{X}$ \\
\hline & Leader & $\mathrm{X}$ & $\mathrm{X}$ & $\mathrm{XX}$ & $\mathrm{X}$ & $\mathrm{X}$ & $\mathrm{X}$ & $\mathrm{XXX}$ & $\mathrm{X}$ & XXX & $\mathrm{XX}$ & $\mathrm{X}$ \\
\hline & Health Advocate & $\mathrm{X}$ & $\mathrm{X}$ & XXX & XXX & $\mathrm{X}$ & $\mathrm{X}$ & $\mathrm{X}$ & $\mathrm{X}$ & $\mathrm{XX}$ & XXX & $\mathrm{X}$ \\
\hline & Scholar & $\mathrm{XXX}$ & $\mathrm{X}$ & $\mathrm{X}$ & $\mathrm{X}$ & $\mathrm{X}$ & $\mathrm{X}$ & $\mathrm{X}$ & $\mathrm{XXX}$ & $\mathrm{X}$ & $\mathrm{X}$ & $\mathrm{XXX}$ \\
\hline \multirow{3}{*}{ 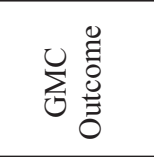 } & Scholar and a Scientist & $\mathrm{XXX}$ & $\mathrm{X}$ & $\mathrm{X}$ & $\mathrm{X}$ & $\mathrm{X}$ & $\mathrm{X}$ & $\mathrm{X}$ & $\mathrm{XXX}$ & $\mathrm{X}$ & $\mathrm{X}$ & $\mathrm{XXX}$ \\
\hline & Practitioner & $\mathrm{XXX}$ & XXX & XXX & $\mathrm{XX}$ & $\mathrm{XXX}$ & $\mathrm{XXX}$ & $\mathrm{XXX}$ & $\mathrm{XX}$ & $\mathrm{XX}$ & $\mathrm{XXX}$ & $\mathrm{XX}$ \\
\hline & Professional & XXX & XXX & XXX & $\mathrm{XX}$ & $\mathrm{XX}$ & XXX & $\mathrm{XXX}$ & $\mathrm{XX}$ & XXX & XXX & $\mathrm{XX}$ \\
\hline \multirow{6}{*}{ 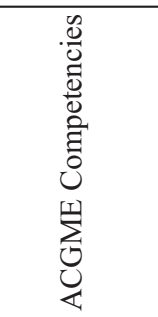 } & Patient care & XXX & XXX & XXX & $\mathrm{XX}$ & XXX & XXX & XXX & $\mathrm{XX}$ & $\mathrm{XX}$ & XXX & $\mathrm{XX}$ \\
\hline & Medical knowledge & $\mathrm{XXX}$ & XXX & XXX & $\mathrm{XX}$ & $\mathrm{XXX}$ & $\mathrm{X}$ & $\mathrm{X}$ & $\mathrm{X}$ & $\mathrm{X}$ & $\mathrm{XX}$ & XXX \\
\hline & Practice-based learning \& improvement & $\mathrm{XX}$ & XXX & XXX & XXX & $\mathrm{XXX}$ & $\mathrm{XXX}$ & $\mathrm{XXX}$ & $\mathrm{XX}$ & $\mathrm{XX}$ & $\mathrm{XXX}$ & $\mathrm{XX}$ \\
\hline & Interpersonal and communication skills & $\mathrm{X}$ & $\mathrm{XX}$ & XXX & $\mathrm{X}$ & $\mathrm{XX}$ & XXX & $\mathrm{XXX}$ & $\mathrm{XX}$ & $\mathrm{XX}$ & $\mathrm{XX}$ & $\mathrm{X}$ \\
\hline & Professionalism & $\mathrm{XX}$ & XXX & XXX & $\mathrm{XX}$ & $\mathrm{XX}$ & XXX & $\mathrm{XXX}$ & $\mathrm{XX}$ & XXX & $\mathrm{XXX}$ & $\mathrm{XX}$ \\
\hline & Systems-based practice & XXX & $\mathrm{XXX}$ & XXX & $\mathrm{XX}$ & $\mathrm{XXX}$ & $\mathrm{XXX}$ & $\mathrm{XXX}$ & $\mathrm{XX}$ & $\mathrm{XX}$ & $\mathrm{XXX}$ & $\mathrm{XX}$ \\
\hline
\end{tabular}

X-Relatively low emphasis $\quad$ XXX-Relatively high emphasis

Programme Outcome of MBBS Programme at EUSL

1. Scientific knowledge in medical practice 2. Clinical and procedural skills 3. Patient management 4. Medico-legal work 5. Health promotion and disease prevention 6. Communication and interpersonal skills 7. Teamwork and leadership 8. Problem solving and research 9. Planning and management 10. Ethics and professionalism 11. Lifelong learning and continuing professional development ing, laboratory work, fieldwork, atcome which is highly associated with international standards is explained in Table-1.

\section{Challenges}

The outcome based curriculum embraces many rewards such as neglected topics are highlighted, time is not fixed, hence a student, could reach the target according to his ability rather than concentrating to finish within a time frame. Students take responsibility of their own learning. Creates confidence in students which is needed in professional practice ${ }^{15,16}$.

It is possible that outcome based curriculum will increase the period needed for some students. Thus, it may be hard to predict the graduation date. This will be a challenge for those students. The additional challenges are organizing selfregulated, flexible learning opportunities and assessing students for competencies.

The individualization that is indicated by outcome based education (OBE) can create greater student motivation and initiative and assist them to pursue their distinctive interests. On the other hand, such individualization and flexibility is extremely demanding for a medical school to manage ${ }^{16}$. Other main challenge is whether this curriculum in written format, is practiced by all the teachers based on the concept of OBE.

\section{Conclusion}

The constructive alignment is highly considered in the outcome based curriculum of MBBS programme in the EUSL. Though there are some questionable challenges to practice the curriculum, it can be noted that this curriculum not only have specific features but also it satisfies the current trends and needs of the medical education in the country as well as in the world.

\section{References}

1. McNeir G. Outcomes-Based Education. [Washington, D.C.]: Distributed by ERIC Clearinghouse; 1993.

2. Spady, W. Outcome-based Education. [Belconnen, ACT.]: Distributed by Australian Curriculum Studies Association; 1993.

3. Gruppen L, Mangrulkar R, Kolars J. The promise of competency-based education in the health professions for improving global health. 2017.

4. Albanese M, Mejicano G, Mullan P, Kokotailo P, Gruppen L. Defining characteristics of educational competencies. 2017. 
5. Biggs, J.B. Teaching for quality learning at university: What the student does. [2nd edn. Philadelphia, PA]: Distributed by Society for Research into Higher Education; 2003.

6. Sri Lanka Qualifications Framework (SLQF) [Internet]. Ugc.ac.lk. 2017 [cited 3 October 2017]. Available from: http://www.ugc.ac.lk/en/all-notices/1156-sri-lankaqualifications-framework.html

7. Graduate Profiles [Internet]. Massey.ac.nz. 2017 [cited 4 November 2017]. Available from: http://www. massey.ac.nz/massey/fms/AVC\%20Academic/Teachin g\%20and \% 20Learning\%20Cenrtres/Graduate $\%$ 20Profiles\%20Quick\%20Guide.pdf?3E50EAF8825B7 DDAAD22007099C04122

8. Mordica, J., Nicholson-Tosh, K. Curriculum alignment module. [Champaign, IL.]: Distributed by Office of Community College Research and Leadership, University of Illinois at Urbana-Champaign; 2013.

9. Outcomes-Based Teaching and Learning (OBTL) [Internet]. Chtl.hkbu.edu.hk. 2017 [cited 3 October 2017]. Available from: http://chtl.hkbu.edu.hk/main/ teaching-and-learning/obtl/

10. Medicine subject benchmark statement [Internet]. Quality Assurance Agency, UK. 2002 [cited 7 November 2017]. Available from: http://www.qaa.ac.uk/ academicinfrastructure/benchmark/honours/medicine
11. Standards for Assessment and Accreditation of Primary Medical Programs by the AMC 2012 [Internet]. Australian Medical Council Limited. 2017 [cited 4 August 2017]. Available from: http://www.amc.org.au/ files/d0ffcecda9608cf49c66c93a79a4ad549638bea0_o riginal.pdf

12. The Royal College of Physicians and Surgeons of Canada: CanMEDS Framework [Internet]. Royalcollege.ca. 2017 [cited 13 December 2017]. Available from: http://www.royalcollege.ca/rcsite/ canmeds/canmeds-framework-e

13. GMC | Home [Internet]. Gmc-uk.org. 2017 [cited 13 December 2017]. Available from: https:/www.gmcuk.org/

14. About Us [Internet]. Acgme.org. 2017 [cited 10 December 2017]. Available from: http://www.acgme. org/About-Us/Overview

15. Harden R. AMEE Guide No. 14: Outcome-based education: Part 1-An introduction to outcome-based education. Medical Teacher. 1999;21(1):7-14. https://doi. org/10.1080/01421599979969

16. Gruppen L. Outcome-Based Medical Education: Implications, Opportunities, and Challenges. Korean Journal of Medical Education. 2012;24(4):281-285. https://doi.org/10.3946/kjme.2012.24.4.281 